Sefarad, vol. 80:1, enero-junio 2020, págs. 25-54

\title{
Revisión y nuevas contribuciones al límite meridional y oriental de la segunda judería de Valencia y fijación de los límites de la tercera y última judería: 1390-1392-1492*
}

\author{
Concepción López González** \\ Universitat Politècnica de València \\ ORCID ID: https://orcid.org/0000-0001-7542-3559 \\ Santiago Máñez Testor*** \\ Investigador independiente \\ ORCID ID: https://orcid.org/0000-0002-4344-8732
}

La puerta de la muralla árabe de Valencia denominada de en Esplugues es el principal referente utilizado para la delimitación de los dos últimos recintos judaicos que tuvo la ciudad. Esta puerta se ha localizado en un lugar diferente al tradicionalmente establecido demostrando que las juderías valencianas tuvieron menor superficie de la que hasta ahora se ha considerado. Asimismo se dispone sobre un plano parcelario actual el perímetro de la tercera judería, localizando los hitos que se mencionan para su delimitación en el privilegio de Juan I de 1393 atendiendo a datos extraídos de otros documentos que apoyan su nueva ubicación.

Palabras clave: Judería de Valencia; Puerta d'en Esplugues; muralla árabe de Valencia; urbanismo medieval.

Review and New Contributions to the Southern and Eastern Boundary of the Second Jewish Quarter of Valencia and Fixing of the Limits of the Third and Last Jewish Quarter: 1390-1392-1492.- The door of the Arab wall of Valencia

* Abreviaturas utilizadas: $\mathrm{ACA}=$ Archivo de la Corona de Aragón; AMV= Archivo Municipal de Valencia; APRCC $=$ Archivo de Protocolos del Real Colegio de Corpus Christi; ARV $=$ Archivo del Reino de Valencia; SMV $=$ Sotsobreria de Murs e Valls Queremos expresar nuestro sincero agradecimiento a los revisores de este artículo por sus inestimables aportaciones.

**mlopezg@ega.upv.es

***santiago@carohotel.com

Copyright: (C) 2020 CSIC. Este es un artículo de acceso abierto distribuido bajo los términos de la licencia de uso y distribución Creative Commons Reconocimiento $4.0 \mathrm{In}$ ternacional (CC BY 4.0). 
called en Esplugues is the main reference used for the delimitation of the last two Jewish sites that the city had. This door has been located in a different place from the traditionally established one, showing that the Valencian Jewish quarters had a smaller area than has been considered so far. Likewise, the perimeter of the third Jewish quarter is located on a current parcel plan, locating the milestones mentioned for its delimitation in the privilege of Juan I of 1393, based on data extracted from other documents that support its new location.

Keywords: Jewry of Valencia; Door d'en Esplugues; Arab Wall of Valencia; Medieval urbanism.

\section{AnTECEDENTES}

La presencia de población judía en España tuvo su comienzo en la costa mediterránea y poco a poco fue extendiéndose por toda la península. A finales del imperio romano ya existían comunidades judías perfectamente consolidadas ${ }^{1}$. Sus actividades mercantiles y artesanales implicaban asentamientos en núcleos de población importantes. Es a partir del comienzo de la Baja Edad Media cuando se incrementan los documentos relativos a la actividad de los judíos y, por tanto, es el período desde el que se tiene mayor conocimiento de las aljamas. En el reino de Valencia cabe destacar los estudios realizados por Magdalena Nom de Deu relativos a las juderías de la provincia de Castellón ${ }^{2}$ así como los de Piles Ros sobre la judería de Burriana ${ }^{3}$ y los llevados a cabo por Hinojosa Montalvo sobre juderías valencianas ${ }^{4}$ y más concre-

1 Concilio de Elvira a comienzos del siglo IV.

2 José Ramón Magdalena Nom De Deu, «La aljama de judíos de Segorbe durante la Baja Edad Media», Miscelánea de estudios árabes y hebraicos. Sección de hebreo 44 (1995) págs. 121-148; y «Nuevos datos sobre la Aljama judía de Castellón de la Plana», Anuario de filología 4 (1978) págs. 199-246.

${ }^{3}$ Leopoldo Piles Ros, «La judería de Burriana. (Apuntes para su estudio)», Sefarad 12 (1952) págs. 105-124.

4 José Ramón Hinojosa Montalvo, Judios y juderías en el reino de Valencia (Valencia: Consell Valencià de Cultura, 2011), y «Sinagogas valencianas (1383-1492)», Sefarad 38: 2 (1978) págs. 293-307. 
tamente sobre las de Xátiva ${ }^{5}$, Sagunto ${ }^{6}$ y Valencia ${ }^{7}$. Esta última contó con una importante población de religión judía que precedió a la conquista de Jaime I en el año 1238. Este monarca, una vez tomada la ciudad, permitió expresamente la residencia de los judíos que lo deseasen, estableciendo los límites de la que sería la primera judería o juheria vella y cuyos lindes han sido fijados entre otros por Francisco Danvila ${ }^{8}$, José Rodrigo Pertegás ${ }^{9}$ y Concepción López ${ }^{10}$ (vid. figura 1).

Este recinto, de planta cuadrangular, tenía una superficie aproximada de $15.600 \mathrm{~m}^{2}$ y en él se ubicaban 95 casas $^{11}$. Disponía de salida directa de la ciudad a través de la puerta de la Xerea estando situada su puerta principal, denominada de la Figuera, en el lado opuesto (vid. figura 1).

Esta forma regular de la planta con salida directa a una puerta de la muralla de la ciudad es una constante que se repite en otras juderías valencianas como la de Morella ${ }^{12}$, cercana a la puerta del Forcall y

5 José Ramón Hinojosa Montalvo, «La judería de Xàtiva en la Edad Media» Espacio, tiempo y forma. Serie III, Historia medieval 6 (1993) págs. 377-408, y La judería de Xàtiva en la Edad Media (Xàtiva: Ajuntament de Xátiva, 1999). Premi d'Investigació Històrica "Sarthou Carreres" 1998.

6 José Ramón Hinojosa Montalvo, «Apuntes para la demografía de la aljama judía de Sagunto en los siglos bajomedievales», Sefarad 55:2 (1995) págs. 273-284.

7 José Ramón Hinojosa Montalvo, The Jews in the Kingdom of Valencia. From the Progroms to the Expulsion (1391-1492) (Jerusalem: The Magnes Press - The Hebrew University, 1993); Los judios en tierras valencianas (Valencia: Institució Alfons el Magnànim, 1999), y La judería de Valencia en la Edad Media (Valencia: Ajuntament de València, 2007), y Marilda Azulay Tapiero y Estrella Israel, La Valencia judía (Valencia: Consell Valencià de Cultura, 2009).

${ }^{8}$ Francisco Danvila y Collado, «Clausura y Delimitación de la Judería de Valencia en 1390 a 1391», Boletín de la Real Academia de la Historia 18 (1891) págs. 142159. Edición Digital. Biblioteca Virtual Miguel de Cervantes (2005).

9 José Rodrigo y Pertegás, La Judería de Valencia (Valencia: Establecimiento tipográfico hijos de F. Vives Mora, 1913). Copia facsímil (Valencia: París-Valencia, 1992).

${ }^{10}$ M. ${ }^{a}$ Concepción López GonzÁLEZ, «Nuevas Aportaciones al estudio del recinto de la judería de Valencia delimitado en 1244», Sefarad 74:1 (2014) págs. 7-31.

11 Llibre del Repartiment entrada 3314 de la edición de FERrando i Frances (Valencia: Vicent García editores, 1979).

12 Manuel Grau Montserrat «La judería de Morella (s. XIII-XIV)», Sefarad 22 (1962) págs. 69-81, y 24 (1964) págs. 288-321. 


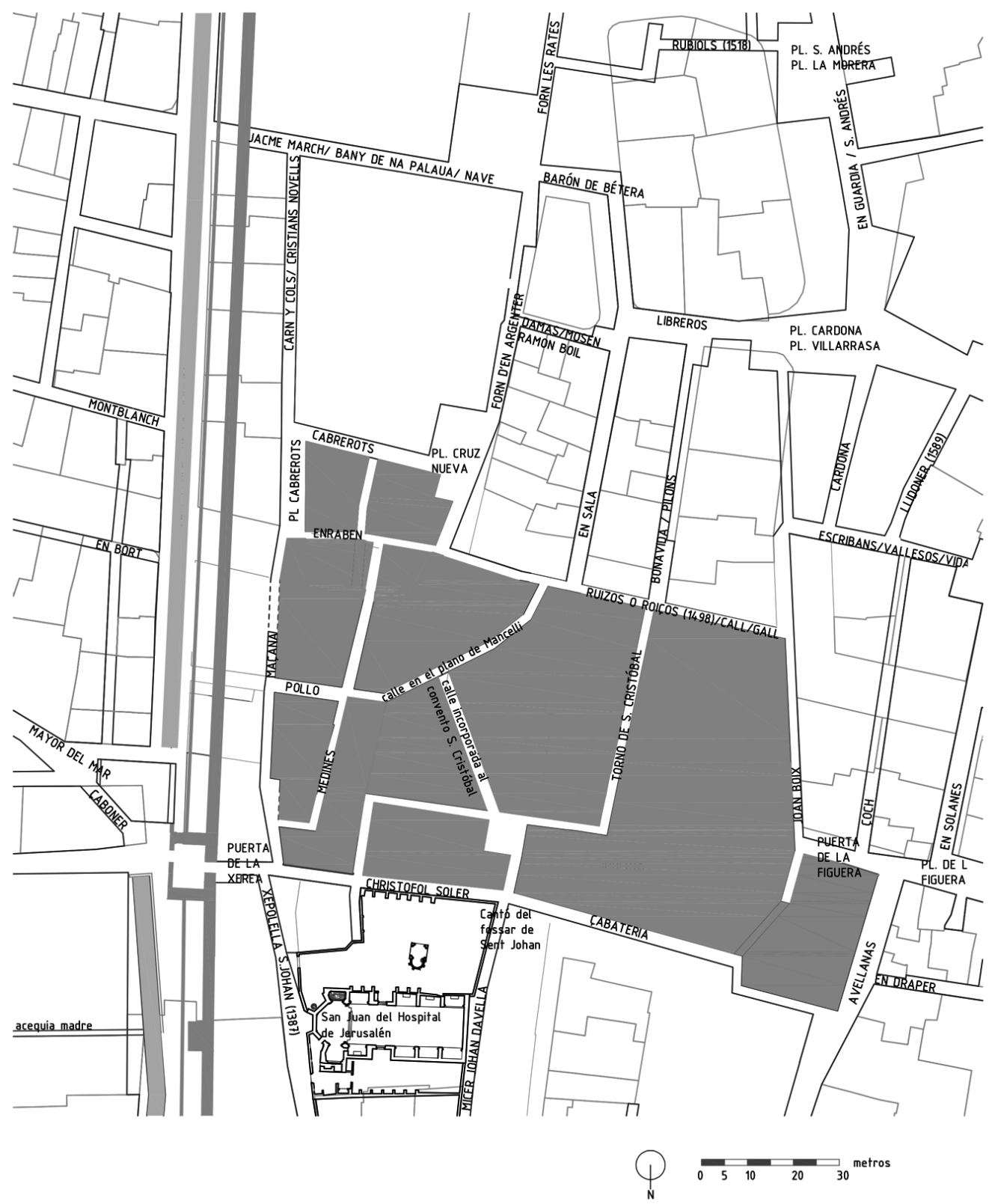

Figura 1. Área que ocupaba la primitiva judería de Valencia sobre el parcelario actual según Concepción López González. 
delimitada por las calles de Blasco de Alagón al norte, San Nicolás al sur, Cuesta de San Juan al este y Cuesta del Palau al oeste; en Castellón de la Plana ${ }^{13}$ estaba determinada por las actuales calles de Mealla al oeste, Cervantes al sur, Auxías March al este y la muralla (Calle San Luis) al norte formando también un paralelogramo con salida a la puerta d'en Trullols; en Burriana ${ }^{14}$ estaba delimitada por las actuales calles de la Sangre, llamada a mediados del s. XVIII calle de la Judería y Santa Teresa disponiendo, como en los casos anteriores, de salida a la Puerta de Tortosa; en Villarreal ${ }^{15}$ se situaba en la antigua calle Judería actualmente calle de San Luis Gonzaga formando un cuadrilátero con salida al portell d'en Pedrinyà; en Sagunto ${ }^{16}$ hubo una importante judería ubicada en el área fijada por las calles del Castell, Sang Vella, Segovia, Ramos, Queralt, Antigons y Pelayo, formando el núcleo central las calles de Segovia, Sang Vella y Ramos con salidas directas al exterior de la ciudad por las puertas recayentes a la actual calle del Castillo que comunicaba con el cementerio (vid. figura 2).

La judería valenciana era, junto con la de Sagunto, una de las más grandes del reino de Valencia, sin embargo este primer recinto vio pronto sobrepasados sus límites y la población judía ocupó a lo largo de la segunda mitad del siglo XIII y durante el XIV nuevas zonas alrededor de la antigua aljama, creando una situación jurídica cuanto menos alegal, ya que en principio no se permitía la convivencia de miembros de ambas religiones, dando lugar a una difícil situación, que fue denunciada reiteradamente por la Iglesia y miembros de la oligarquía religiosa, entre

13 José Ramón Magdalena Nom de Deu, La aljama hebrea de Castellón de la Plana en la Baja edad Media (Castellón: Sociedad Castellonense de Cultura, 1978) pág. 111.

14 Norberto Mesado Oliver, «Prólogo», en José Ramón Magdalena Nom de Deu, La aljama de judios de Burriana (siglos XIII-XV) (Borriana: Ajuntament de Borriana, 1978) pág. 9.

15 José M. a Doñate Sebastiá y José Ramón Magadalena Nom De Deu, Three Jewish communities in Medieval Valencia, Castellón de la Plana, Burriana, Villarreal (Jerusalem: The Magnes Press - The Hebrew University, 1990).

16 Matías Calvo Gálvez, «Espacios singulares de la judería de Sagunto» en De Murbiter a Morvedre (Valencia: Fundació Bancaixa, 2006) págs. 239-245. 


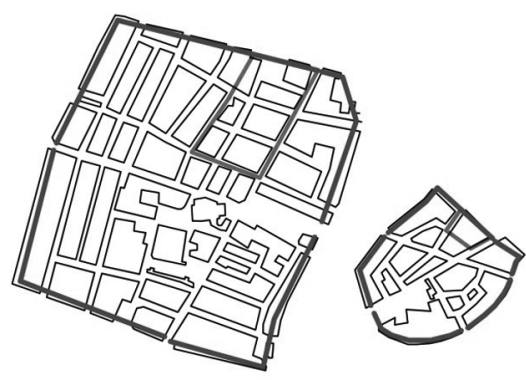

CASTELLON

BURRIANA

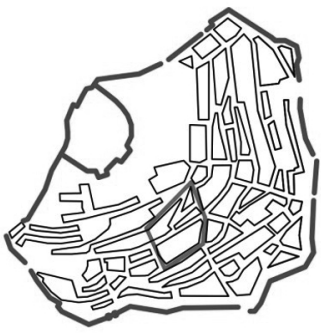

MORELLA

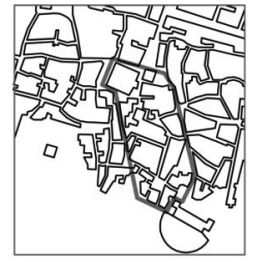

SAGUNTO

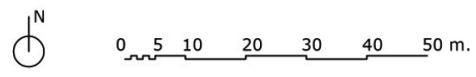

Figura 2. Área que ocupaban las juderías de Castellón, Burriana, Morella y Sagunto.

ellos por San Vicente Ferrer. Fruto de estas quejas ${ }^{17}$, las Cortes convocadas por el monarca Juan I y celebradas en Monzón el 29 de noviembre de 1389 acuerdan reconocer la nueva realidad urbana, es decir, la extensión de la nueva judería y proceder a su cierre ${ }^{18}$. En cumplimiento de dicho acuerdo el Consell de Valencia nombra ${ }^{19}$ el 19 de febrero de 1390 varios comisarios para ejecutarlo, llevándose a cabo el cierre durante todo el año 1390 y parte del 91. El coste de las obras fue asumido por la ciudad, que nombró para su control al notario D. Luis de Menarques, quien al consignar por escrito los pagos por actuaciones llevadas a cabo en su perímetro, ha permitido establecer con bastante precisión ${ }^{20}$ las

${ }^{17}$ Es probable que la decisión real tuviese más bien una doble intención de contentar a unos y proteger a otros, pues la relación de cristianos y judíos se encontraba muy deteriorada en todo el reino.

18 El cierre se acuerda por fuero de 1 de Diciembre; $c f$. Danvila y Collado, «Clausura y Delimitación...», pág. 150.

19 AMV Manual de Consells, 19 A, fol. 107v; cf. Rodrigo y Pertegás, La judería de Valencia, pág. 9.

${ }^{20}$ Hay que tener en cuenta no obstante, que para facilitar el cierre, el Consell acordó el 19 de febrero de 1391 demoler algunas casas de judíos y otras de cristianos, lo que modifica aunque de forma muy limitada y puntual el recorrido original. 
dimensiones de la que pasaría a denominarse juheria nova o segunda judería.

Esta juheria nova fue brutalmente asaltada por turbas enloquecidas el día 9 de julio de 1391, quienes, además de asesinar a decenas de personas ${ }^{21}$, robaron en viviendas y profanaron las sinagogas, acto que casi supuso la desaparición de la judería, ya que tras el asalto muchos de sus vecinos procedieron a su abandono, en vista de lo cual Juan I y su esposa Violante, a la sazón beneficiaria de sus rentas, acordaron su disolución el siguiente año 1392, según consta en documento fechado en 2 de octubre ${ }^{22}$, en el que se reservaron no obstante el derecho a reconstruir la judería si lo considerasen oportuno.

Efectivamente, en privilegio de fecha 31 de diciembre de $1393^{23}$ al que nos hemos de referir, los reyes acuerdan la reconstrucción de una nueva aljama y una nueva judería valenciana, pero esta vez con unas dimensiones mucho menores a la anterior: es la tercera judería de Valencia que, pese a los esfuerzos de Juan I, no llegó a prosperar, quedando algunos judíos de forma residual ${ }^{24}$.

Años más tarde, toda esta zona sería definitivamente desmantelada por el Patriarca de Antioquía, San Juan de Ribera, al levantar el Real Colegio de Corpus Christi a finales del siglo XvI.

Pretendemos en este artículo continuar la labor de nuestros predecesores en el estudio de la judería valenciana, introduciendo algunas notas que permiten conocerla mejor, modificando sus límites, reubicando una de sus puertas de acceso, y fijando el perímetro de la tercera judería.

${ }^{21}$ Las cifras difieren entre las más de 100 personas consignadas en la documentación municipal, hasta más de 200. En este sentido, véase Hinojosa Montalvo, La judería de Valencia en la Edad Media, págs. 89-90.

22 ACA, C, reg. 1905, fols. 89v y ss; cf. Hinojosa Montalvo, The Jews of the Kingdom of Valencia, págs. 259 y doc. págs. 368-369.

23 ACA, C, reg. 1905, fols. 89v y ss.

${ }^{24}$ Hinojosa Montalvo, La judería de Valencia en la Edad Media, pág. 107. 


\section{LA PoRTA D'EN ESPLUGUES Y EL LIMITE ORIENTAL DE LA SEGUNDA Y TERCERA JUDERÍA}

Es habitual en los estudios históricos del urbanismo que la documentación existente haga referencia de forma reiterada a determinados hitos físicos que, una vez ubicados, permiten la reconstrucción de amplios espacios urbanos a partir de su localización.

Para la delimitación de la segunda y tercera judería valenciana también se han utilizados algunos enclaves para su definición. Cabe destacar un portal cristiano abierto en la muralla islámica denominado d'en Esplugues, que ha servido a los historiadores ${ }^{25}$ de punto de partida para identificar los límites meridional y oriental de la segunda (juheria nova, 1389) y tercera judería (1393) de Valencia.

Si observamos las descripciones realizadas por Danvila y Rodrigo Pertegás, ambos autores establecen como uno de los hitos fundamentales del recorrido de la juheria nova, el Portal d'en Esplugues, en base a los apuntes que figuran en el libro de cuentas del cierre de la Judería consignada en 1391 por el ya citado notario Luis de Menarques a la sazón encargado del control de costes del levantamiento del muro que la clausuraría.

Igualmente, la tercera y última judería, viene definida en el acuerdo al que se ha hecho referencia dictado en 1393 por Juan I donde aparece precisamente el portal d'en Esplugues como punto de partida y mojón que marca la línea divisoria entre la zona cristiana y la judía:

$[\ldots]$ et redendo ad dictum portale vocatum d'en Esplugues tota pars sinistra sit et remaneat de dicta nova iudaria et infra eam tota pars dextra et remaneat ad usum christianorum et extra iudaria.

Por ello es esencial ubicar este portal en el actual parcelario para conocer el límite meridional de la segunda y tercera judería, localización que, no obstante su importancia, es controvertida.

${ }^{25}$ La gran mayoría de historiadores y aficionados que han tratado los límites de la judería son deudores de Danvila y Rodrigo Pertegás. 
Danvila lo sitúa, siguiendo a Carboneres ${ }^{26}$, al final de la calle Barcelona en su cruce con la actual calle de la Universidad, y Rodrigo Pertegás en la confluencia entre la calle Salvá y la calle de las Barcas, donde la muralla islámica realizaba un giro hacia el oeste. Con esta localización, ambos autores, y los que los siguieron, han venido incluyendo dentro del ámbito de la judería valenciana la manzana donde se levanta la Universidad de Valencia (vid. figura 3).

Sin embargo, un análisis de los documentos que hacen referencia a este portal indica que su situación pudo ser diferente a la establecida por Danvila y Rodrigo Pertegás lo que obligaría a redefinir el límite meridional de la segunda y tercera judería.

El portal d'en Esplugues tiene su origen en el privilegio ${ }^{27}$ de 1298 por el que el rey Jaime II permite a su baile general, Bernardo de Esplugues, abrir un portal en la muralla islámica de Valencia entre el portal del Trabuquet y el de Xerea:

Nos Jacobus rex Aragorum etc. volumus et vobis fideli nostro Bernardo d'Espeluncis bajulo Regni Valentie generali concedimus de gratia spetiali ut in muro civitatis Valentie inter portam vocatam del Trabuquet et portam de la Exerea possitis facere et construere sive construi et facere de novo quoddam pa allum in illo loco ubi vobis melius visu fuerit infra spatium dictarum portarum dum tamen hoc juratis dicte civitatis videant et cognoscant quod possit fieri sine dampno et preiudicio nostro et civitatis predicte. Datum Valentie idus aprilis anno Domini. M. ${ }^{\circ} .{ }^{\circ}{ }^{\circ}{ }^{\circ}$.xc. ${ }^{\circ}$.viij 28 (13 de abril de 1298).

La extensión de muralla entre el portal del Trabuquet y el de Xerea es muy amplia por lo que es necesario acudir a los documentos que

${ }^{26}$ Manuel Carboneres y Quiles, Nomenclátor de las Puertas, Calles y Plazas de Valencia (Valencia: Imprenta Avisador Valenciano, 1873). Edición Facsímil (Valencia: Paris Valencia, 1980) pág. 3

27 ACA, C, reg. 196, fol. 197v; apud Rodrigo y Pertegás, La judería de Valencia, pág. 16.

28 Deseamos a vos fiel nuestro Bernardo Esplugues, baile general del reino de Valencia, concederte de gracia especial a fin de que en el muro de la ciudad de Valencia entre la puerta denominada del Trabuquet y la puerta de la Xerea puedas hacer y construir y hacer de nuevo algún portal en el sitio donde mejor veas bajo el espacio de dichos portales, mientras no obstante los jurados de la ciudad vean y conozcan donde puedas hacerlo sin daño y perjuicio nuestro y de la citada ciudad (traducción de los autores). 
hacen referencia al portal d'en Esplugues para determinar verazmente su ubicación:

Hinojosa Montalvo ${ }^{29}$ cita un documento de 13 de junio de 1407, donde se indica que la calle de Jaume March está ubicada «al portal d'en Splugues». También Carboneres ${ }^{30}$ identifica el portal d'en Esplugues con el portal de en Jacme March, citando a la Sotsobreria de Murs $i$ Valls de los años 1396 y 97. Encontramos otros documentos de comienzos del siglo Xv donde vuelve a identificarse la calle d'en Esplugues con la d'en Jacme March. En este sentido citamos la nota de la SMV de $1416^{31}$, donde se hace constar que el sotsobrer entrega 235 sueldos y 8 dineros a Lluis de Menargues por las obras realizadas en una acequia nueva en la calle de n'Esplugues o d'en Jacme March.

Por otro lado, en fechas posteriores, la calle d'en Esplugues fue también denominada calle del Bany de na Palaua, al menos en su tramo perteneciente a la Parroquia de San Andrés, tal y como consta en la nota de la Sotsobreria de Murs $i$ Valls de 27 de octubre de $1433^{32}$, que recoge el apunte del sotsobrer de los gastos en jornales por la limpieza de los fosos de la ciudad en las bóvedas de la calle «d'en Esplugues alias del Bany de na Palaua». Asimismo recibe este nombre en el contrato de compraventa al que hace referencia Hinojosa Montalvo de una casa en la calle del «Bany de na Palaua alias d'en Jacme March»» ${ }^{33}$ de fecha 16 de mayo de 1444. Por su parte, el Ostal de na Palaua, estaba en el carrer d'en Esplugues ${ }^{34}$ (vid. figura 3).

Ya a finales del siglo xv la calle que inicialmente se denominó de Jacme March y posteriormente del Bany de na Palaua pasa a denominarse calle de la Nao según documento notarial de 13 de agosto de 1487,

29 José Ramón Hinojosa Montalvo, Una Ciutat Gran i Populosa. Toponimia y urbanismo en la Valencia medieval (2 vols. Valencia: Ayuntamiento de Valencia, 2014) pág. 745 .

30 CARboneres y Quiles, Nomenclátor de la puertas..., pág. 3.

31 AMV, SMV, d3-24, fol. 160v; citado por M. ${ }^{a}$ Milagros CÁrCel OrTí, «Vida y Urbanismo en la Valencia del siglo xv», Regesta Documental, Miscel-lania de Textos Medievals 6 (1992) págs. 255-628: 414.

32 AMV, SMV, d3-36, fol. 103r; cf. CÁrCEL OrTí, «Vida y Urbanismo...», págs. 505.

33 APRCC, Protocolo de Lleonart Çamorera, n. ${ }^{\circ} 26.128$.

34 AMV, Libres de Avehinament, b3-4, 5. ${ }^{\mathrm{a}}$ mano, fols. 4v-5r. 


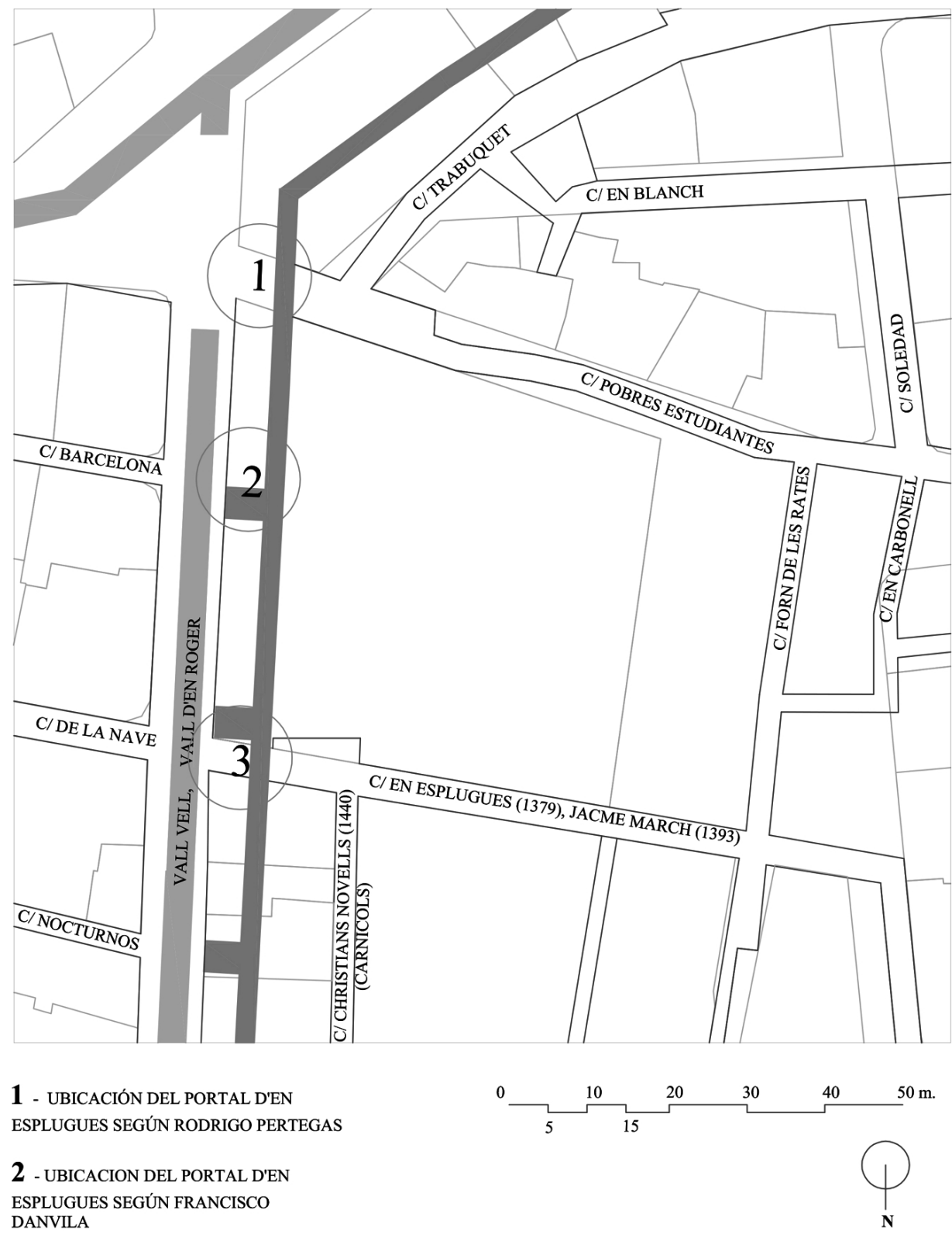

3 - UBICACIÓN DEL PORTAL D'EN ESPLUGUES SEGÚN LOS AUTORES

Figura 3. Ubicación del portal d'en Esplugues según diferentes autores. 
en el que consta la venta de una casa sita «[...] in vico vulgariter dicto d'en Jacme March o de la Nao» ${ }^{35}$. Y en este mismo sentido consta apunte en el Libre de Avehinament de fecha 10 de abril de 1464 del avecindamiento del cirujano Ferrando Pérez, en el «carrer d'en Jacme March davant l'ostal de la Nau» ${ }^{36}$. Por último, cuando el sotsobrer de la Obra de Murs $i$ Valls anota el 22 de mayo de $1408^{37}$ los gastos por hacer una acequia en la calle d'en Esplugues, hace constar que se inicia en la casa de Scuder y va hasta la Draçana (atarazana), es decir, está definiendo el recorrido de la calle de la Nave.

De la lectura de todos estos documentos se puede colegir que la calle d'en Esplugues es la misma calle que en la actualidad denominamos de la Nave y que anteriormente se denominó de Jacme March y del Bany de na Palaua. Si como se ha visto el portal d'en Espluges estaba ubicado en la calle d'en Jacme March, resulta evidente que este portal se encontraba en la actual calle de la Nave, alias d'en Jacme March, d'en Esplugues y del Bany de na Palaua. Y como quiera que el portal se abrió en la antigua muralla islámica, debió levantarse llegando a la confluencia con la actual calle de la Universidad (vid. figura 3).

Al variar la ubicación de este portal, se puede observar que los terrenos sobre los que se levantaría más tarde la Universidad de Valencia, quedaban fuera del perímetro de la segunda judería y, así mismo, del tercer recinto por ser la calle de la Nave su límite meridional como más adelante se verá. Se puede afirmar que los terrenos sobre los que se levantó la Universidad nunca pertenecieron a la judería, pues no pertenecieron a la primera, y cómo hoy vemos, tampoco a la segunda ni a la tercera, modificándose así el límite meridional y variando considerablemente su tamaño.

35 A.R.V., Protocolos de Juan de Campos, pág. 445; apud Hinojosa Montalvo, Una ciutat gran i populosa, pág. 745.

36 AMV, Libres de Avehinament, b3-6, fol. 28r.

37 AMV, SMV, d3-19, fol. 27r; apud CÁrCel OrTí, «Vida y Urbanismo...», pág. 363. 


\section{El portalet vers lo bany d'en Esplugues: la Pobla d'en ESPLUGUES}

Es necesario señalar que el portal d'en Esplugues, abierto en la muralla árabe en 1298 dando acceso a la ciudad a través de la calle de la Nave, fue derribado en las obras del cercado de la segunda judería ya que en esas fechas ya existía la muralla cristiana y los portales de la muralla árabe tendían a desaparecer. Los materiales del derribo fueron utilizados para ser nuevamente construido como puerta de acceso al nuevo recinto judaico según consta en el libro de gastos de Luis Menarques. Este nuevo portal era denominado comúnmente portalet d'en Esplugues o portalet vers lo bany d'en Esplugues ${ }^{38}$ dado que se trataba de un portillo más que de un portal y así se diferenciaba del desaparecido portal d'en Esplugues.

Los documentos indicados y los que se citan a continuación permiten ubicar el pequeño portal.

Francisco Danvila ${ }^{39}$, recoge la escritura notarial del protocolo de Arnaldo Ferrán de 1337 donde se especifica que la casa de en Esplugues está «[...] espatlles al Vall-Vell, cantó a lo portell dels juheus, ab porta al carrer den Esplugues».

Esta cita según la cual la casa de Esplugues estaba de espaldas al Vall Vell (muralla islámica), esquina al portal de los judíos y con puerta a la calle d'en Esplugues, sitúa la casa d'en Esplugues en la actual calle de la Nave lindando con la muralla árabe.

Por su parte, según hemos indicado, el rey Juan I al señalar los límites de la nueva judería (tercera de las que tuvo la ciudad), hace constar: «Et primo incipiendo a quondam modico portali vocato d'En Esplugues, constituto ante hospicium Vicentius Saranyo $[\ldots]^{40} \gg$, es decir, el reco-

38 Acuerdo Real de 14 de Diciembre de 1392; cf. Hinojosa Montalvo, Una ciutat gran i populosa, pág. 697.

39 Protocolo notarial de Arnaldo Ferrán de 1337 donde se especifica que la casa de en Esplugues está «[...] espatlles al Vall-Vell, cantó ab lo portell dels juheus, ab porta al carrer den Esplugues»; apud Danvila y Collado «Clausura y Delimitación de la Judería de Valencia en 1390 a 1391», pág. 153.

40 ACA, C. reg., 1.905, fol. 89v; citado en Rodrigo y Pertegás, La judería de Valencia, p. 17. También en Hinojosa Montalvo, La judería de Valencia en la Edad Media, pág. 105. 
rrido de la judería se inicia en el pequeño portal d'en Esplugues ubicado frente a la casa de Vicente Saranyó.

Esta casa es la que años más tarde comprarían los jurados de la ciudad a los herederos de Vicente Saranyó para fundar el Estudio General de la Universidad de Valencia ${ }^{41}$ :

Los magnífichs mossén Gaspar Pellicer, en Perot Splugues, en Luís Granolles e en Benet Vidal, jurats, en Benet Llorenç, racional, e lo síndich, ajustats en casa del dit magnífich mossén Gaspar Pellicer, proveexen que lo clavari comú pague xvm. sous a la magnífica na Isabel Saranyo, muller de mossén Pere Saranyo, quondam, per preu de hun alberch que la dita ciutat ha comprat de la dita na Isabel Saranyo ab carta rebuda per lo scrivà en lo present dia per fer un Studi per a studiar, proveynt que lo síndich ne faça carregament ab asentiment prestat a xvi. de octubre Lxxxxii e lo poder del Consell a xxviii. de setembre any Lxxxx.

El acuerdo transcrito y la escritura consiguiente de fecha 1 de abril de 1493 recogidas por Vives Liern ${ }^{42}$ nos permiten situar la casa de Vicente Saranyó en la calle de la Nave, y lo que es más importante, también ubica en esta calle y junto a dicha casa el Baño de Isabel Saranyó:

Dicha compraventa se realizó ese mismo día 1 de abril de 1493 y ante el Escribano de la «Sala», Gaspar Eximeno, la Magnífica Isabel Saranyo, viuda de Pedro Saranyo, Caballero é Isabel Saranyo, hija de ambos, vendieron á los Justicia, Jurados y Síndico de Valencia, repre-

41 Vicente Vives y Liern, Las Casas de los Estudios de Valencia (Valencia: Talleres de Imprimir Vda. de Emilio Pascual, 1902) pág. 83.

42 Vives y Liern, Las Casas de los Estudios, pág. 85: Prosiguieron las obras para el ensanche del edificio, agregando varias casas compradas á Mosén Luis de Valeriola (1) Jaime Gallent, Antonio Salces, Rodrigo Morales, Jaime Landrich, Juan Cicilia, Juan March (2) y otros. (3):

(1) Archivo Municipal de Valencia. - Manual de Consells. - Años 1497-99. Núm. 49, sig.» A.

(2) Archivo Municipal de Valencia. - Manual de Consells. - Años 1499-1502. Núm. 50, sig.* A. - Provisiones de 17 Octubre y 14 de Noviembre de 1499, 26 de Septiembre de 1500 y 30 de Enero de 1502.

(3) En el libro titulado "Escrituras de casas y tierras de la Ciudad de Valencia", aparecen las de compras hechas para el ensanche del Estudio General, desde el año 1502 en adelante. - Archivo Municipal de Valencia. 
sentando á la misma, cierto hospicio ó casa que fue de dicho Pedro Saranyo, franco y quito, situado en la parroquia de San Andrés, con dos huertos contiguos, en uno de los cuales había dos patios [...] cuya casa, huertos y patios lindaban al todo con dos vías públicas, con la casa y patio del Baño de Isabel Saranyo, con el Muro viejo de la Ciudad, con cierto azucat ó calle sin tránsito, con las casas del honorable Luis March, mercader, y con cierta plaza en la que tenía la puerta el precitado hospicio ó casa.

Conviniéronse además otras condiciones para conseguir el total aislamiento de la Casa-Baño, propia de la vendedora, á fin de que nadie, por ninguna parte, pudiera ver dicho Baño, siendo entre esas condiciones la principal que, á expensas de la Ciudad, se construyese la pared divisoria ó mediera de ambos edificios, sin dejar ninguna ventana ó agujero. $\mathrm{Y}$, por último, estipulóse también que la puerta principal de la casa comprada, no pudiera abrirse á la calle mayor en donde el Baño tenía la suya, sino que continuara en la plaza á que recaía y recayó siempre.

Por su parte, Josep Guía recoge un importante documento sobre este baño: se trata de un contrato de arrendamiento formalizado el 4 de julio de 1485 por doña Isabel Saranyó, en el que arrienda a favor de Beltrán Picart, calçater, y su mujer Catalina «[...] balneum sive bany meum, situm et positum in parrochia sancti Andree, dictum vulgarum lo bany de moceen Saranyó o de na Palaua»» ${ }^{43}$.

De esta forma, se evidencia que el bany de na Palaua es el mismo que el de moceen Saranyó. Y sabemos que este último es el d'en Esplugues, según consta en la cita del justicia civil de Valencia al sacar a subasta los bienes de Marco Boyso, que vivía delante del bany d'en Saranyó o d'en Esplugues ${ }^{44}$.

En definitiva, nos encontramos ante un solo baño con tres nombres, y por ello el portalet vers lo bany d'en Esplugues estaría frente al baño de na Palaua o d'en Esplugues 45 o d'en Saranyó.

43 ARV, Protocolo de Joan Casanova, n. ${ }^{\circ}$ 6163; apud Josep GuIA I Marín, «Lo Bany de na Palaua: Nous documents sobre els origens d'El Estudi General de València» en Historia de Valencia (Valencia: Levante EMV, 1999).

44 ARV, Justicia civil, n. ${ }^{\circ} 4312$, fol. 44r; $c f$. Hinojosa Montalvo, Una ciutat gran i populosa, pág. 344 .

45 Todavía en 1403 seguía denominándose Bany d'en Esplugues (AMV, Libres de Avehinament, b3-3. fol. 297v), y en 1409 ya aparece la calle del Bany de na Palaua 
Para ubicar mejor este baño, y por tanto el pequeño portal, se han recabado otras informaciones que definen dónde se encontraba exactamente. La referencia más importante la proporciona un documento ${ }^{46} \mathrm{de}$ fecha 2 de abril de 1440 donde se indica que el Bany de na Palaua está frente a la calle dels cristians novells.

Asimismo, en el documento de compraventa de dos casas de Francisco Díez, panadero, para la construcción del Colegio del Patriarca fechado el 15 de marzo de 1587, se indica que una de ellas hace esquina a la calle de la Nave y a la que va hasta la plaza de Cabrerots lindando con el baño de na Palaua, dicha calle de la Nave en medio ${ }^{47}$. De ello se deduce que el baño se encontraba frente a la casa que hacía esquina a la calle de la Nave y a la actual calle de San Juan de Ribera o dels cristians novells. La denominación de la calle hace referencia a los judíos conversos. El Padre Tosca, en su plano de 1704, la denomina calle de Carn y Cols. Probablemente se trate de una corrupción del apellido judío Carnicol ${ }^{48}$. La otra casa de Francisco Díez, lindante con la anterior, confrontaba, calle de la Nave en medio, con el horno de na Palaua, por lo que se puede deducir que el horno se encontraba contiguo al baño.

(AMV, Libres de Avehinament, b3-3. fol. 348r). Transcritas en M. . Desamparados CAbanes Pecourt, Avecindados en la Ciudad de Valencia en la época Medieval. Avehinaments (1308-1478) (= Col·lecció "Arxiu Municipal” 2 [Valencia: Ajuntament de València, 2008]).

46 Citado por Hinojosa Montalvo, Una ciutat gran i populosa, pág. 356.

47 En el Archivo del Real Colegio de Corpus Christi se conserva el libro original Anónimo de 1600, Libro de Compras de casas encorporadas en el Collegio y Seminario fundado por el Illustrisimo señor Don Juan de Ribera, Patriarcha y Arcobispo de Valencia. En 1892 se hizo una copia anónima que es a la que hemos tenido acceso: Libro de Construcción y Fábrica, fol. 64r: "Con auto de venta otorgado ante Gaspar Mico notario en quinze de Março de mil quiniento [sic] ochenta y siete, Francisco Diez flaquero...vendieron...dos casas derribadas puestas en esta ciudad de Valencia, En la parrocuia [sic] de San Andrés en la calle dicha de la Nau que confinan con horno dicho de Napalaua, y con baño dicho del estudio general, la dicha calle de la Nau en medio y con casas del dicho colegio compradas por su Ilma. de Simon Moncada y con calle por la cual se va à la plaçuela dicha antiguamente de los cabrerots».

${ }^{48}$ En 1383 el baile general impuso una serie de multas a diversos judíos entre los que figuraba Carnicols; $c f$. José Ramón Magdalena Nom De Deu, «Delitos y “calonies” de los judíos valencianos en la segunda mitad del siglo XIV (1351-1384)», Anuario de filología 2 (1976) págs. 181-226: 206. 
Efectivamente, Josep Guia ha localizado un contrato de donación del Bany de na Palaua a favor de la hija de Isabel Saranyó en fecha 28 de noviembre de 1494 donde consta que dicho baño lindaba con el horno de Joannis Ros:

[...] quodam balneo meo vulgariter dicto lo bany de na Palaua, francho et quitio, sito et posito in parrochia Sancti Andree, confrontato ex uno latere cum furno sive clibano Joannis Ros, flaquerii, et ex alio latere cum domibus civitatis Valentie, que esse solebant mei, dicte Ysabelis Saranyo, et per me fuerunt dicte civitat Valentie et eius sindico vendite et alienate, et cum vico publico quo itur al Hostal de la Nau. Et ex parte retro confrontatur cum horto domorum dicte civitatis Valentie et cum dicto furno et cum muro veteri ${ }^{49}$.

Y siguiendo este planteamiento, es importante citar la escritura de fundación del Colegio de Corpus Christi ${ }^{50}$, donde se recogen los lindes del citado colegio conocido hoy como del Patriarca: «[...] la plaza dicha de los Cabrerots y de dicha plaça a la calle de la Nao delante del horno vulgarmente dicho de $\mathrm{Na}$ Plana o del estudio general». La denominación de Na Plana se debe considerar una corrupción por el paso del tiempo de na Palaua. Por tanto ya tenemos el binomio horno-baño que podemos identificar con el baño y horno de Bernat Esplugues ${ }^{51}$ otorgado en 1296 por Jaime II a tan ilustre personaje que había sido baile general ${ }^{52}$, y que formaba parte de la pobla ${ }^{53}$ de Bernat de Esplugues, que pasaría a ser

49 ARV, Protocolo de Baromeu de Càrries, n. ${ }^{\circ}$ 20449; apud GuIA I MARÍN, «Lo Bany de na Palaua...», págs. 667-668.

${ }^{50}$ LóPez GonzÁLEZ, Nuevas aportaciones..., pág. 7-31

51 Este horno aun sería denominado d'En Esplugues en 1378, como se acredita en los documentos referentes a un proceso ante el Justicia Criminal en fecha 16 de agosto de 1378, según Hinojosa Montalvo Una ciutat gran i populosa, pág. 553.

52 Concha Camps García y Joseph Torró Abad (El Palacio y los Baños del Almirante [Valencia: Generalitat Valenciana, Conselleria d'Economia, Hisenda i Ocupasió, 2001]) recogen el texto por el que se otorga a Bernat d'Esplugues licencia de construcción de un baño en sus posesiones de la ciudad cuando y donde quiera.

${ }^{53}$ Pobla, Popula, es una actuación urbana integrada, en la que se urbaniza una parcela o conjunto de parcelas por uno o varios propietarios, que actúan cómo promotores, encaminadas a uso particular y a la obtención de rentas con su establecimiento a censo. Las poblas son actuaciones aisladas, completamente privadas y sin dirección por parte de las de las autoridades locales, pero su papel en la urbanización de la Valencia 
años más tarde, al menos en parte, propiedad de Vicente Saranyó, y sobre la que se levantaría finalmente el Estudio General de la Universidad. Este baño perduró hasta mediados del siglo XVII. Orellana cita la existencia de un baño denominado bany del Studi todavía en pie en el año 1658 y que identifica con el de na Palaua ${ }^{54}$.

Todo ello confirma que el portalet vers lo bany d'en Esplugues, estaría ubicado al inicio de la calle Cristians Novells, actual calle de San Juan de Ribera, en el cruce con la calle de la Nave, cerrando la judería en esta calle, ubicación lógica si tenemos en cuenta que el límite meridional del barrio lo marcaba precisamente la calle de la Nave y que desde dicho portal existía una salida directa de la ciudad a través del portal denominado tradicionalmente Portal de los Judios de la nueva muralla cristiana recientemente construida.

\section{LOS LÍMITES DE LA TERCERA JUDERÍA}

La delimitación que tuvo el tercer recinto de la judería queda perfectamente estipulada en el privilegio de fecha 31 de diciembre de $1393^{55}$ firmado por Juan I. Con la nueva ubicación del portalet d'en Esplugues y siguiendo el recorrido que se describe en dicho documento vamos a aproximar dicha delimitación al parcelario actual.

En primer lugar describe el recorrido del límite oriental:

Et primo incipiendo a quodam modico portali vocato d'En Esplugues constituto ante hospicium Vicentius Saranyo, per quod portale iam ante destruccionem dicte prime aliame ad tunc iudariam seu callum dicte civitatis Valentie habeatur ingressus sequendo a parte interiori versus vallum totum murum veterem dicte civitatis usque ad quemdam vicum per quem de dicto vallo itur ascendendo versus hospicium vocatum d'En

medieval tiene gran relevancia, y cada día se muestra mayor su importancia conforme va pareciendo nueva información sobre las mismas.

54 Marco Antonio de Orellana, Valencia antigua y moderna. Tomo I (Valencia: Acción bibliográfica valenciana, 1923) Edición facsímil (Valencia: París-Valencia, 1985) pág. 154

55 ACA, C, reg. 1905, fols. 89v-91r. El texto completo ha sido extraído de Hinojosa Montalvo, La judería de Valencia en la Edad Media, págs. 105-106. 
Roger usque ad plateam vocatum dels Cabrerots remanentibus dicto hospicio den Roger et aliis hospiciis illius partis eiusdem vici ad usum christianorum et extra dictam iudariam et alia pars dicti vici videlicet de dicto vallo seu muro usque ad dictam plateam dels Cabrerots sit et remaneat de dicta iuderia ${ }^{56}$.

Del texto se desprende que el cierre oriental de esta judería lo marcaba el muro de la muralla árabe (murum veterem). Discurría en el espacio comprendido entre el portalet d'en Esplugues, construido para dar acceso al barrio judío situado frente a la casa de Vicente Saranyo (ante hospicium Vicentius Saranyo), y cierta calle donde se encontraba el alberch $^{57}$ d'en Roger por la que se accedía a la plaza de Cabrerots. La casa d'en Roger y todas las que se encontraban en su lado de la calle, así como la propia calle quedaban fuera de la aljama.

Este alberch debe situarse en la manzana entre la plaza de San Vicente Ferrer y una calle o callejón hoy desaparecido que conectaría el foso (vallum) con la plaza de Cabrerots, situación similar a la que fija Rodrigo Pertegás ${ }^{58}$. Así se deduce del acuerdo del Consell de 1402 y que transcribimos:

Item proveí lo dit Consell que la torre del alberch appellat d'en Roger attinent ${ }^{59}$ del portal de la Exerea, lo qual es huy den Pere Làzer, lo qual en Pere Làzer ha començada derrocar sia acabada de derrocar com

56 Primero empieza en el pequeño portal llamado d'en Esplugues construido ante la casa de Vicente Saranyó por el cual portal antes de la destrucción de la primera aljama en aquel entonces se ingresaba a la judería o call de la ciudad de Valencia siguiendo por la parte interior del vall todo el muro antiguo de la ciudad hasta cierta calle por la cual dicho vall asciende hacia la casa llamada de en Roger y la plaza llamada de Cabrerots quedando dicha casa de en Roger y otras casas de esa parte de la calle para uso de cristianos y fuera de la judería. Y la otra parte de dicha calle, es decir, de dicha pared de la muralla hasta la plaza de Cabrerots a mano izquierda queda la judería (trad. de los AA.).

57 Alberch: Aunque es un tema debatido, el término valenciano aberch/alberg, parece referirse en las fuentes de los siglos XIV y XV, a vivienda, casa, sin especificar la categoría real del inmueble.

58 Rodrigo y Pertegás, La judería de Valencia, pág. 17.

59 Attinent: el término debe traducirse como 'junto a' o 'pared con pared'. Así aparece (a veces simplemente "tinent") en muchos textos medievales. Un ejemplo relevante es el «Testamento de Jaume Roig de 1478», publicado en Jaume J. CHINER MoRENO, «Del testamento e inventario de bienes de Jaume Roig al autor del manuscrito del 
a vista e dita de molts en la forma que esta estía no solament le més perillos $[\ldots]^{60}$

El texto deja claro que estaba cercano a la puerta de la Xerea, es decir, en la propia muralla islámica, y dotado de una torre perteneciente a dicha cerca.

La razón de dejar fuera del recinto esta casa (alberg), se debe a la constante de conseguir que la judería estuviera dentro de la circunscripción de una única parroquia, y en el caso de la tercera judería esta quedaba dentro de la parroquia de San Andrés, mientras que el alberg d'en Roger pertenecía a la parroquia de San Esteban, como es de ver en un protocolo de $1399^{61}$.

La calle que conectaba el vall con la plaza de Cabrerots a la que hace referencia el documento debía ser un callejón actualmente desaparecido situado como continuación de la calle En Bort del que aún se conserva un pequeño atzucach en el plano de Tosca (1704) (vid. figura 4).

Rodrigo Pertegás hace coincidir la plaza de Cabrerots con la plaza de la Cruz Nueva ${ }^{62}$ y esta teoría la han seguido algunos autores. Sin embargo son dos plazas distintas como demuestra el propio texto de la delimitación del tercer recinto y los documentos de compra-venta para la construcción del Real Colegio Seminario de Corpus Christi en los que

\footnotetext{
"Spill”. Documentos y nuevas hipótesis», Butlletí de la Reial Acadèmia de Bones Lletres de Barcelona 44 (1993-1994) págs. 173-230.

${ }^{60}$ Citado en José Sanchis Sivera, La Iglesia Parroquial de Santo Tomás de Valencia: Monografia histórico-descriptiva. (Valencia: Establecimiento tipográfico Hijos de F. Vives Mora, 1913) pág. 159. Provee el dicho Consell que la torre de la casa llamada del señor Roger siguiente al portal de la Xerea, la cual es hoy de Pere Làzer, el cual Pere Làzer ha comenzado a derribar sea acabada de derribar... (trad. de los AA.).

${ }^{61}$ En un documento de compra-venta se vende «cierta casa llamada d'en Roger situada en la parroquia de San esteban...que confronta con la casa de Bartolomé Vela y con la casa de Johannis Bausteran y con la casa de Anthoni Riera y con la casa del rector de Gandía y con otra cierta casa en el adzucach antes judería y con la vía pública y con el vall viejo llamado en Roger vía pública en medio». ARV, Protocolo De Bartolomé de la Mata de 6 de noviembre de 1399; apud Rodrigo y Pertegás, La judería de Valencia, pág. 17.

62 «La plaza dels Cabrerots, de capacidad é importancia muy superiores á la que ahora tiene la plazuela de la Cruz Nueva que la sustituye...»; apud RodRIGO Y PERTEGÁs, La judería de Valencia, pág. 25.
} 


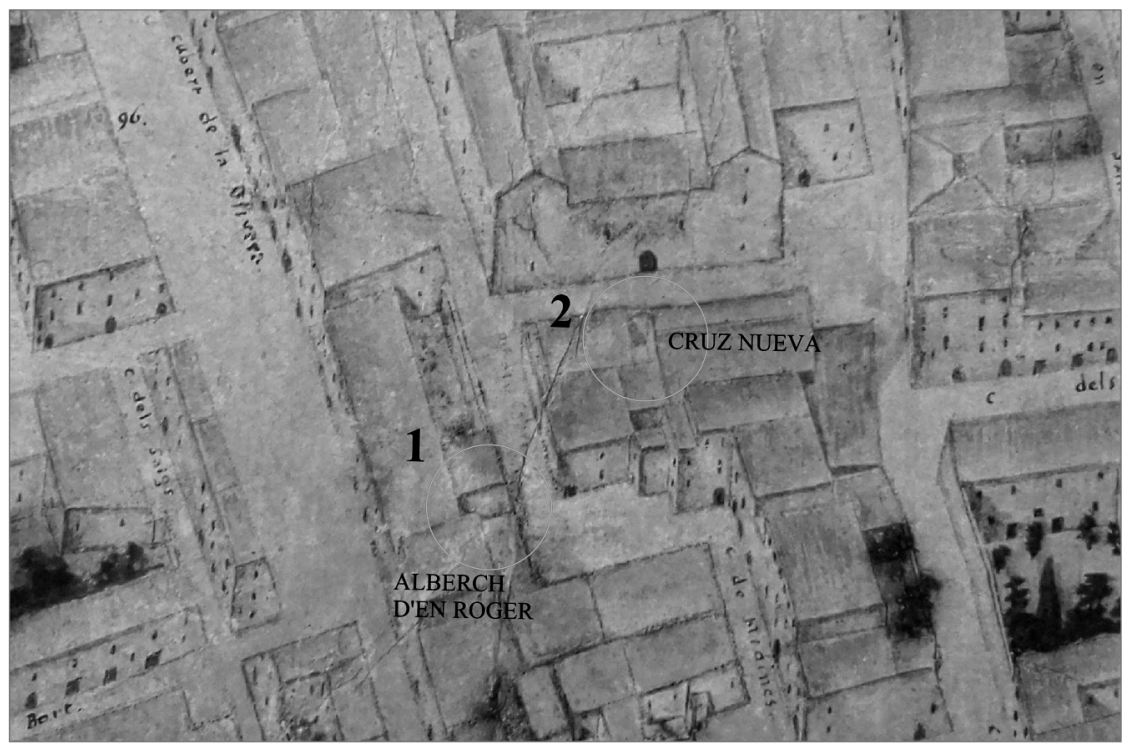

1 - ATZUCACH DE LA CALLE QUE COMUNICABA EL MURO CON LA PLAZA DE CABREROTS DONDE SE SITUABA EL ALBERCH D'EN ROGER

2 - ATZUCACH DE LA CALLE JUDERIA A ESPALDAS DE LA ERMITA DE LA CRUZ

0

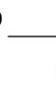
$40 \quad 50 \mathrm{~m}$ NUEVA

Figura 4: Plano de Tosca (1704) con los vestigios de la calle que unía el muro de la cerca árabe con la plaza Cabrerots y la calle Judería.

muchas de la propiedades adquiridas se encuentran en «la calle que và de la plaçuela dicha de la cruz nueva à la plaçuela dicha de los cabrerots» ${ }^{63}$. La plaza de la Cruz Nueva ha mantenido el nombre hasta la actualidad y en ella se encontraba a partir del siglo XVI la iglesia que

${ }^{63}$ Libro de Construcción y Fábrica: «Con auto de compra otorgado ante Francisco Hieronimo Metaller en veynte y tres de noviembre mil quinientos y ochenta $\mathrm{m}^{\circ}$ Pedro Martin Rector del lugar de Maniças vendió... una casa, o patio de casa drirruyda ... la puerta de la cual atapada està en la calle que và de la plaçuela dicha de la cruz nueva à la plaçuela dicha de los cabrerots, que confina con casas ... que solian ser de Nicolás Aguerri y con corral o casa de m. ${ }^{\circ}$ Miguel Estelles clérigo...». 
le daba nombre y que según Escolano ${ }^{64}$, Orellana y Pertegás pudo ser anteriormente Sinagoga. A principios del siglo XVIII se utilizaba como escuela de primaria ${ }^{65}$. La plaza de Cabrerots, según se desprende del documento anteriormente citado y del plano de Tosca que la ubica con precisión, se encontraba al final de la calle Carn y Cols también llamada de Cristians novells, actual calle de San Juan de Ribera.

Una vez en esta plaza, el texto continúa estableciendo el límite septentrional:

Et in dicta platea ad manum sinistram usque ad aliud cantonum ad manum sinistram vici ascendentis ad hospicium magistri Petri d'Arters, conversus, olim vocatus magister Humer Tahuell fiat clausura sive tanqua cum portali per quod ad dictam novam iudariam habetur ingressus ${ }^{66}$.

Continuaba la cerca por la esquina izquierda de la calle donde se encontraba el alberg d'en Roger y que llevaba a la casa del magister Pere d'Arters, médico judío converso antes llamado Humer Tahuell ${ }^{67}$, pasando por el portal de entrada a la nueva judería que debía ser abierto.

Desde el nuevo portal de acceso la línea divisoria seguía por el lado izquierdo de la calle que conducía a la casa del magister Pere d'Arters hasta la otra esquina en donde todavía persistía el portal de acceso a la antigua judería y continuaba hasta llegar a la esquina donde sobresalía la casa de Pascual Maçana. Con esto concluye la descripción del límite septentrional utilizando la misma fórmula que anteriormente utilizó al

${ }^{64}$ Gaspar Juan Escolano, Década primera de la historia de la insigne y coronada ciudad y Reyno de Valencia (Valencia: Pedro Patricio Mey a costa de la Diputación, 1610) Libro 5, cap. 18, col. 1028-1029.

65 De Orellana, Valencia antigua y moderna, vol. I, págs. 506-507.

66 Y la otra parte de dicha calle, es decir, de dicha pared de la muralla hasta la plaza de Cabrerots a mano izquierda hasta la otra esquina a mano izquierda de la calle que asciende a la casa del magister Petri d'Arters, converso, antes llamado Humer Tahuell sigue la clausura o cierre por el portal por el que se ingresa a la nueva judería (trad. de los AA.).

${ }^{67}$ Sobre la familia de médicos Tahuell, véase el completísimo artículo de José Ramón Hinojosa Montalvo, «Médicos judíos en la ciudad de Valencia durante la baja Edad Media (siglos XIII y XIV)», en Estudos em homenagem ao Profesor Doctor José Marque (Porto: Faculdade de Letras da Universidade do Porto, 2006) págs. 415-436. 
definir el límite oriental: toda esta parte de la izquierda de la calle pertenece a la judería y la calle y el lado derecho es cristiano:

Et de proximo dicto cantono vici predicti magistri Petri d'Arters, sequendo dictum vicum usque ad aliud cantonum, in quo ante novas seu ultimas clausuras dicte antique iudarie consueverat esse portale usque ad quod cantonum venit seu protenditur hospicium Paschasii Maçana, conversus, olim vocatus N'Açan Abenmarueç sit et remaneat in iudaria tota pars sinistra, remanente ad usum christianorum et extra iudarian vico et tota partita hospiciorum que est versus hospicia dicti magistri Petri d'Arters et Rogerii de Montcada, conversus, olim vocatus Issach Abdolaziz et Jacob Coffe, iudeus ${ }^{68}$.

Vamos a ubicar los hitos que se mencionan: la calle del magister Pere d'Arters podemos identificarla como la continuación de la calle que unía el vall con la plaza de Cabrerots. En el plano de Tosca esta calle ya ha sido absorbida por las edificaciones, sin embargo, en el plano de Mancelli (1608) se observa claramente un atzucach o callejón sin salida como vestigio de lo que fue la calle del magister Pere d'Arters (vid. figura 5).

El portal de acceso a la antigua judería, tal y como se menciona en el texto, se encontraba entre la plaza dels Cabrerots y la casa de Pascual Maçana. Siguiendo la delimitación establecida para la antigua judería sobre el parcelario actual (vid. figura 1), así como las indicaciones del plano de Rodrigo Pertegás, este portal se encontraba en la confluencia de la calle del magister Pere d'Arters con la plaza de la Cruz Nueva.

Según indica el texto de delimitación, el acceso a la nueva judería se debía abrir entre la plaza de Cabrerots y este antiguo portal. Probablemente se situaba en la confluencia con la denominada calle Judería que corría a espaldas de la iglesia de la Cruz Nueva según se detalla en el

${ }^{68} \mathrm{Y}$ de dicha esquina de la calle del magister Pere d'Arters, siguiendo dicha calle hasta la otra esquina en que antes del cierre de la nueva o última clausura, dicha antigua judería conserva el portal hasta llegar a la esquina donde sobresale la casa de Pascual Maçana, converso, antes llamado n'Açan Abenmarueç, es y queda toda la judería en la parte izquierda quedando para uso de los cristianos y fuera de la judería la calle y toda la partida de casas que están hacia la casa de magister Pere d'Arters y Roger de Montcada, conversos, ante llamado Isaach Abdolaziz, y Jacob Coffe, judío (trad. de los AA.). 


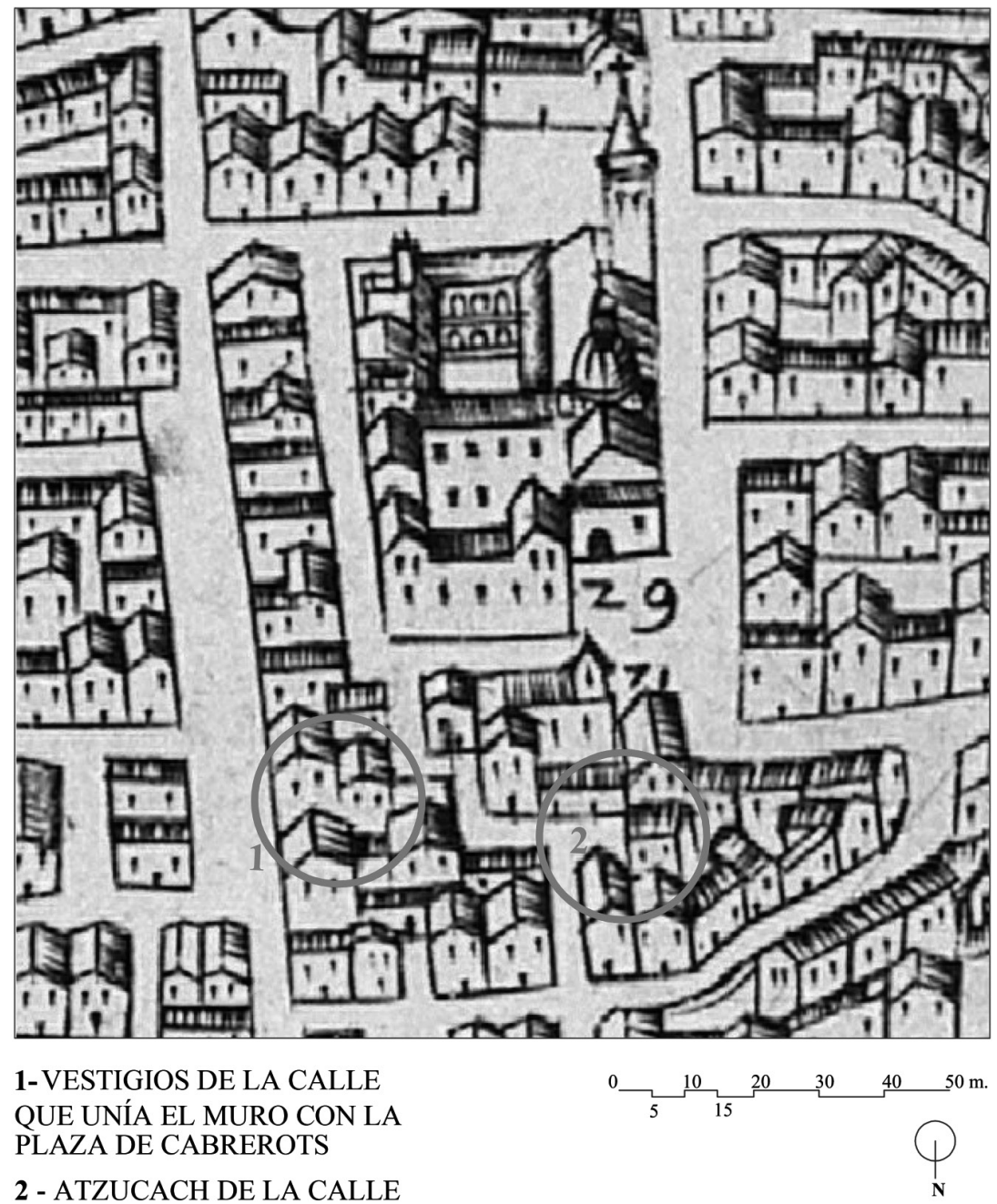

\section{DEL MAGISTER PETRI}

Figura 5: Vestigios de la calle que unía el muro de la cerca árabe con la plaza de Cabrerot y de la calle del magister Petri d'Arters (Humer Tahuell).

Libro de construcción y fábrica del Patriarca, donde se registran los documentos de compra-venta de las casas y solares para la construcción del Real Colegio de Corpus Christi. En estos documentos se establece que la casa de Miguel Sunier estaba situada «en la calle dicha de la 
Judería, junto à la plaçuela dicha de los cabrerots» ${ }^{69}$ confinaba con la casa de Miguel Steller situada «en la calle por la qual se và de las espaldas de la capilla, ò, iglesia dicha de la cruz nueva» ${ }^{70}$.

La calle de la Judería, también desaparecida, era continuación de la calle Medines que aún se conserva en la actualidad. Aun puede observarse esta calle que estuvo situada a espaldas de la ermita de la Cruz Nueva en el plano de Tosca de $1704^{71}$ (vid. figura 4, núm. 2).

Desde la esquina donde se conservaba el portal de la antigua judería la delimitación continuaba hasta la esquina donde sobresalía la casa de Pascual Maçana (vid. figura 6).

Continúa el privilegio describiendo el límite occidental y meridional:

Et de dicto cantono ubi est hospitcum dicti Paschasii et Gabriells de Montcada, conversus olim vocatus N'Açam et Samuel Tori, usque ad lapidem cantonum hospicii quodfuit Juceffi Abengalell. Et de próximo dicto cantono usque ad cantonum magnum N'Açan Abenmaruez, quondam, et inde sequendo clausuram del azucach que debet dirui et redeundo ad dictum portale vocatum d'En Esplugues tota pars sinistra sit et remaneat de dicta nova iudaría et infra eam et tota pars dextram remaneat ad usum christianorum et extra iudariam ${ }^{72}$.

${ }^{69}$ Libro de Construcción y Fábrica, fol. 24r.

70 «Con auto de venta ante Francisco Hieronimo Metaller en siete de Junio de mil quinientos ochenta y seis el dicho $\mathrm{m}^{\circ}{ }^{\circ}$ Miguel Steller ... vendió ... una casa puesta en la parrochia de San Andres en la calle por la cual se và de las espaldas de la capilla, ò, iglesia de la cruz nueva à la plaçuela dicha de los cabrerots...»; Libro de Construcción y Fábrica, fol. 45r.

${ }^{71}$ En el plano de Mancelli de 1604 la ermita de la Cruz Nueva se designa con el número 71. En el plano de 1704 está grafiada la ermita pero no se encuentra listada en el nomenclátor. En el grabado de Fortea de 1738 aparece en el nomenclátor con el número 56.

$72 \mathrm{Y}$ de dicha esquina donde está la casa de Pascual y Gabriel de Montcada, conversos, antes llamados n'Açam y Samuel Tori, hasta la esquina de piedra de la casa que fue de Jucef Abengalell. Y de la siguiente esquina hasta la gran esquina de n'Açan Abenmaruez, y luego siguiendo la clausura del atzucah que debe ser derribada y retornando al portal llamado d'en Esplugues toda la parte izquierda es y queda de dicha nueva judería y por debajo de ella y toda la parte derecha queda para uso de los cristianos (trad. de los AA.). 
Desde la casa de Pascual Maçana el cierre continuaba hacia el sur por la actualmente denominada calle de la Cruz Nueva pasando por una serie de casas que sirven de hito para el recorrido que debe seguir la clausura finalizando en el portalet d'en Esplugues donde había dado comienzo.

Estos hitos son fácilmente localizables sobre el plano considerando las calles que existieron en el ámbito que hoy ocupa el conjunto arquitectónico del Patriarca. Estas calles se deducen de los datos extraídos de los documentos de compra-venta de las parcelas que componían la manzana del Real Colegio de Corpus Christi en los cuales se detalla con toda precisión los lindes entre los propietarios y las calles adyacentes. En el límite occidental existían dos calles o atzucach que se internaban desde la actual calle de la Cruz Nueva hacia el interior del solar del Colegio de Corpus Christi: uno de ellos era un callejón sin salida situado frente al horno de la Cruz Nueva tal y como se describe en el documento de compra-venta de Vicente Ferrer ${ }^{73}$, de Luis Joan Tarranch ${ }^{74}$ y de Ysabel Joan de Lisea y de Velasco ${ }^{75}$. El horno de la Cruz Nueva, situado frente a este atzucach, era conocido anteriormente como el forn d'en Argenter ${ }^{76}$ dándole el nombre a la calle ${ }^{77}$.

El otro era la denominada calle Alguaziría, situada más al sur, que daba acceso a trece propiedades: Elvira de la Vega ${ }^{78}$, Nicolás Aguirre que tenía esta propiedad además de la que colindaba con la Iglesia de la Cruz Nueva ${ }^{79}$, Antón Joan Segrera ${ }^{80}$, Pedro Villanueva ${ }^{81}$, Gaspar Serrano ${ }^{82}$,

${ }^{73}$ Libro de Construcción y Fábrica, fol. 11r.

${ }^{74}$ Libro de Construcción y Fábrica, fol. 9r.

${ }^{75}$ Libro de Construcción y Fábrica, fol. 65r.

${ }^{76}$ Hinojosa Montalvo, Una ciutat gran i populosa, pág. 584.

77 Esta denominación podría deberse a que en ella se encontrara la vivienda de J. Argenter, en la partida Algalga, cerca del horno regentado por Br. Forner (Llibre del Repartiment, 3274 y 3272).

78 Libro de Construcción y Fábrica, fol. 5r.

79 Libro de Construcción y Fábrica, fol. 21r.

${ }^{80}$ Libro de Construcción y Fábrica, fol. 29r.

${ }^{81}$ Libro de Construcción y Fábrica, fol. 47r.

${ }^{82}$ Libro de Construcción y Fábrica, fol. 57r. 
Guillermo Hierónimo Alsaruch ${ }^{83}$, Baptista Albert ${ }^{84}$, Pedro Deusa ${ }^{85}$, Antón Bas ${ }^{86}$ y Miguel Ángel Vinader ${ }^{87}$. Esta calle también tenía salida a la calle de la Nave aunque fue clausurada al delimitarse el barrio judío en 1390.

Por lo tanto, la siguiente esquina de sillares de piedra perteneciente a la casa de Jucef Abengalell a la que hace referencia el privilegio coincide con la esquina que formaba la calle del forn d'en Argenter con la calle Alguaziría (vid. figura 6). Continuaba el cierre hasta la gran esquina de otra propiedad de n'Açan Abenmaruez que no puede ser otra que la esquina con la calle de la Nave finalizando en ella el cierre occidental.

Desde aquí continuaba el cierre en su lado meridional por la calle de la Nave hasta el portalet d'en Esplugues, lugar donde había dado comienzo el recorrido (vid. figura 6). Este tramo de cerca coincide con el que tuvo la segunda judería motivo por el cual ya se encontraba cerrado. En este tramo, según el privilegio, existía un atzucach clausurado denominado d'en Vives Abenvives que también tenía salida al tramo de calle entre la esquina de Jucef Abengallel y la de n'Açan Abenmaruez, es decir, coincide con la calle que posteriormente fue denominada Alguaziria. El privilegio también especifica que esta clausura debe ser derribada debido a que en esta área de la judería viven muchos cristianos a los que se les permite continuar viviendo hasta que finalicen las obras de la clausura:

Intelligatur tamen quod quedam domus constructe in dicta pars sinistra a dicta clausura facta ultra dictum cantonum predicti magistri N'açan Aben Maruez et ultra vicum azuçach d'en Vives Abenvives usque ad dictum portalem d'En Esplugues sint et remaneant ad usum christianorum et extra iudariam prout remanserunt tempore confeccionis dicte clausure ${ }^{88}$.

\footnotetext{
${ }^{83}$ Libro de Construcción y Fábrica, fol. 60r.

${ }^{84}$ Libro de Construcción y Fábrica, fol. 66r.

${ }^{85}$ Libro de Construcción y Fábrica, fol. 67r.

${ }^{86}$ Libro de Construcción y Fábrica, fol. 68r.

${ }^{87}$ Libro de Construcción y Fábrica, fol. 69r.

${ }^{88} \mathrm{Se}$ entiende sin embargo, que quedan casas construidas en dicha parte izquierda a dicha clausura hecha desde la esquina de n'Açan Aben Maruez y en el azuçach llamado d'en Vives Abenvives hasta dicho portal d'en Esplugues que son y quedan para uso de cristianos y fuera de la judería durante el tiempo de realización de dicha clausura (trad. de los AA.).
} 


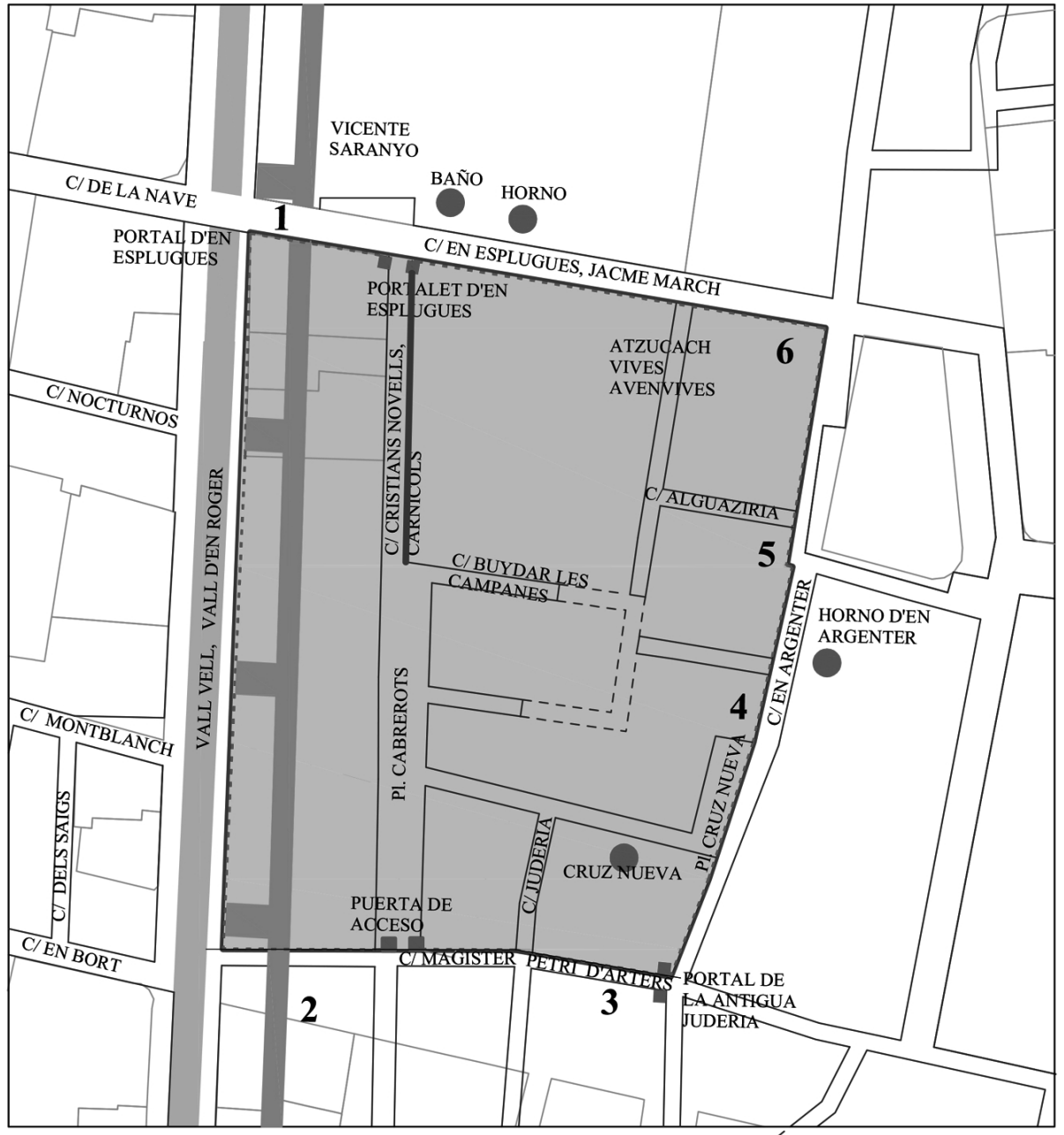

1 - PORTAL D'EN ESPLUGUES

2 - ALBERCH D'EN ROGER

0

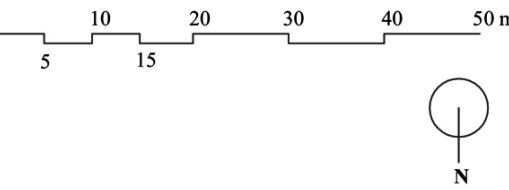

3 - CASA DEL MAGISTER PETRI D'ARTERS (HUMER TAHUELL)

4 - CASA DE PASCHASII MAÇANA (NAÇAN ABENMARUEZ)

5 - CASA DE JUCEFFI ABENGALELL

6 - CASA DE NAÇAN ABENMARUEZ

Figura 6. Delimitación del tercer recinto con la localización de los hitos que se nombran en el privilegio de 31 de diciembre de 1393 de Juan I. 
También deben ser paralizadas las obras de cierre en el tramo que discurre entre la casa de Jucef Abengallel y la de n'Açan Abenmaruez por vivir todavía muchos cristianos en este tramo de calle dejando claro que el atzucach d'en Vives Abenvives puede quedar abierto en sus dos accesos, el de la calle de la Nave y el de la calle d'en Argenter, mientras sigan viviendo cristianos en esta zona:

Volumus et ordinamus que absque periudicio limitationum predictarum dictis limitibusad presens retineantur et deputentur ad opus dictorum iudeorum dictum azucach d'en Vives Abenvives et medietas vici qui est et íncipit inter dicta cantona Juceffi Abengalell et magistri N'Açan Abenmaruez, iudei quondam, videlicet tota illa partita que est de dicto cantono magistri N'Açan usque ad dictum vicum publicum, quo intur ad dictum portalem d'en Esplugues sit tamen que dictum azuçach valeat aperiti versus dictum portalem d'en Esplugues seu versus dictum vicum dicti magistri N'Azam ${ }^{89}$.

De esta forma observamos que la tercera judería de Valencia era muy pequeña, de apenas $5.000 \mathrm{~m} 2$, y un perímetro de $285 \mathrm{~m}$, incluyendo básicamente la plaza dels Cabrerots y el solar que actualmente ocupa el Colegio de Corpus Christi. Al igual que se había ido haciendo desde la conquista cristiana, su forma en planta se corresponde con un cuadrilátero regular y disponía de una salida en el portalet d'en Espugues cercana a la puerta de la muralla cristina denominada tradicionalmente como puerta de los Judíos.

No se han encontrado pruebas documentales que testimonien la construcción de esta tercera cerca del barrio judío. Parece que el intento de Juan I por reconstruir la judería tras el asalto de 1391 no prosperó ${ }^{90} \mathrm{y}$ los conversos y los pocos judíos que se quedaron siguieron viviendo en sus antiguas residencias.

89 Queremos y ordenamos que, sin perjuicio de la limitación anteriormente dicha, que dicha clausura sea detenida por ahora y paralizado el trabajo de dicha judería en el azuçach d'en Vives Abenvives y en la mitad de la calle que es y discurre entre la esquina de Jucef Abengalell y el magister n'Açan Abenmaruez, antes judío, es decir toda la citada partida que hay de dicha esquina del magister n'Açan hasta la dicha calle pública que va al dicho portal d'en Esplugues sin embargo dicho azuçach puede abrir hacia dicho portal d'en Esplugues o hacia dicha calle del magister n'Açan (trad. de los AA.).

90 Hinojosa Montalvo, La judería de Valencia en la Edad Media, págs. 107 y 433. 
El espacio desaparecería incluso físicamente en una interesante actuación urbanística llevada a cabo por el Patriarca de Antioquía entre 1586 y 1604, quien adquirió de su peculio particular 43 propiedades ubicadas entre las calles Nave, Carnicol, plaza de Cabrerots, Cardenal Payá y En Argenter (Cruz Nueva), es decir, prácticamente casi todo el espacio de la tercera judería, para levantar el Real Colegio de Corpus Christi. Esta actuación, llevada a cabo por el entonces Arzobispo de Valencia, no hubiera podido materializarse de no ser por la evidente decadencia, y quizá completo abandono, del espacio que una vez fue destinado a albergar una comunidad judía cuyos avatares corrieron parejos a la suerte de todos aquellos que por seguir la Ley de Abraham, fueron despreciados por el resto de habitantes de las ciudades europeas.

De este ámbito sólo sobrevive en la actualidad la pequeña, estrecha, lúgubre y sombría calle de San Juan de Ribera, la antigua calle de Carnicols, también denominada de Christians Novells.

\section{CONCLUSIONES}

Tras la revisión de la documentación existente relativa al portal d'en Esplugues, ha sido posible concretar su ubicación cierta. Muchos autores con anterioridad habían situado este portal de la cerca árabe de Valencia en diferentes puntos, pero la investigación llevada a cabo confirma que se encontraba en la confluencia de las actuales calles de la Nave y Universidad. Este descubrimiento es especialmente interesante cuando se lo relaciona con el área que ocuparon las diferentes juderías que tuvo la ciudad. No afecta a la delimitación de la juheria vella pero representa un dato fundamental para delimitar la segunda y tercera juderías. Demuestra que estos dos recintos fueron mucho más pequeños de lo que siempre se había pensado ya que el actual edificio de la Universidad, el Estudi General, nunca formó parte de los recintos judaicos. Supone, por tanto, un avance en el conocimiento del entorno urbanístico de estos dos barrios judíos y, por ello, puede ser de gran utilidad para profundizar en el estudio de su cartografía y toponimia.

Recibido: 11/11/2019

Aceptado: 27/02/2020 